\title{
The adsorption of tetrathiomolybdate to iron sulfides
}

\author{
N. W. Miller ${ }^{1}$, R. Du ${ }^{1}$, T. SAUERS ${ }^{1}$, C. YAN ${ }^{1}$, J. Pines $^{1}$, \\ K. E. PlASS ${ }^{1}$, J. L. MORFORD ${ }^{1 *}$ \\ ${ }^{1}$ Chemistry Department, Franklin \& Marshall College, \\ Lancaster, PA 17604, USA (*correspondence: \\ jennifer.morford@fandm.edu)
}

Molybdenum (Mo) has been used as a paleoproxy to provide evidence for past oceanic euxinic and sulfidic conditions. Simultaneous extraction during chemical leaching[1] and adsorption experiments[2] indicate association of molybdenum with pyrite, although a limited amount of Mo has been found in some pyrite phases[3]. Pyrite is not likely to be the initial iron sulfide formed in the environment. We sought, therefore, to experimentally determine the association of Mo with precursors of pyrite, such as mackinawite and greigite, and to determine whether that association is preserved during iron sulfide transformation.

In one method, tetrathiomolybdate was adsorbed to mackinawite or a mackinawite/greigite mixture. The resulting solid phase was examined. This revealed that the adsorption of tetrathiomolybdate was significantly greater to mackinawite and the mackinawite/greigite mixture relative to pyrite with very little change to the mineral upon adsorption.

A second method sought to more closely mimic environmental conditions with the synthesis of mackinawite followed by brief in situ aging and the near-immediate addition of tetrathiomolybdate. The resulting material from the second method was also characterized and then transformed to greigite/pyrite while monitoring Mo release to the aqueous phase. Here, the adsorption of tetrathiomolybdate promoted the transformation of the mackinawite to pyrite upon heating without the concomitant loss of molybdenum to the aqueous phase.

These results support the early capture of tetrathiomolybdate by more amorphous forms of iron sulfide and its retention during iron sulfide phase transformation minimizing concerns about diagenetic loss, with perhaps the adsorption of tetrathiomolybdate promoting the formation of more stable forms of iron sulfide (pyrite).

[1] Huerta-Diaz and Morse (1992) Geochim. Cosmochim. Acta 56, 2681-2702. [2] Freund et al. (2015) Geochim. Cosmochim. Acta 174, 222-235. [3] Chappaz et al. (2014) Geochim. Cosmochim. Acta 126, 112-122. 